\title{
Merging Tibetan Culture into the Chinese Economic Fast Lane
}

The Great Western Development policy should increase immigration from inner China to the Tibet Autonomous Region

\section{Susette Cooke}

\section{(2) OpenEdition}

\section{Journals}

Édition électronique

URL : http://journals.openedition.org/chinaperspectives/775

DOI : 10.4000/chinaperspectives. 775

ISSN : 1996-4617

Éditeur

Centre d'étude français sur la Chine contemporaine

\section{Édition imprimée}

Date de publication : 1 décembre 2003

ISSN : 2070-3449

\section{Référence électronique}

Susette Cooke, "Merging Tibetan Culture into the Chinese Economic Fast Lane », China Perspectives

[En ligne], 50 | november- december 2003, mis en ligne le 19 avril 2007, consulté le 28 octobre 2019.

URL : http://journals.openedition.org/chinaperspectives/775; DOI : 10.4000/chinaperspectives.775

Ce document a été généré automatiquement le 28 octobre 2019.

(c) All rights reserved 


\section{Merging Tibetan Culture into the Chinese Economic Fast Lane}

The Great Western Development policy should increase immigration from inner China to the Tibet Autonomous Region

\section{Susette Cooke}

1 The nature of Tibet's historical situation relative to China ${ }^{1}$, and its current manifestation as the Tibet Autonomous Region (TAR) within the People's Republic of China (PRC), has generated specific administration policies from the central government since the $1950 \mathrm{~s}^{2}$. With the adoption in 2000 of a new national strategy for developing its western regions, China plans a "completely new look" for these areas ${ }^{3}$, not least the TAR, where effects of the Great Western Development (GWD) policy (Xibu da kaifa) are likely to be more profound than for any other provincial-level constituent of the PRC. While the central government has included the TAR as just one of multiple provincial-level components of its new strategy, it has also refocused its specific Tibet policy in tandem with the national project, a recognition of the TAR's distinctive characteristics and problems. Among the PRC's five autonomous regions, all of which are included in the GWD, the TAR's cultural and ethnic characteristics are more homogeneous than in any of the others: a single non-Han culture and nationality dominates the region, who have a clear, commonly-shared self-identity. Ethnic and cultural diversity characterises many of the other areas under the GWD, but before 1950, when the Han Chinese began to arrive in Tibet, one term could sum up everything that was there as Tibetan.

2 For this reason, an account of the GWD's likely impact in Tibet, and local responses to it, are more cogently considered in a cultural perspective than measured economically. At its core, the GWD intends to remould the western areas through a new approach to socialist nationality relations, economic development, and insistence on national unity. Its architects aim for a "profound social transformation"4, intending that few aspects of life will be shielded from its effect. Tibetans see the framing of their future in such terms as certain to result in cultural dilution and marginalisation ${ }^{5}$. At 2.62 million in 2000 , the TAR population forms only $0.7 \%$ of the total population within the GWD area, 
and a mere $0.2 \%$ of the population in the whole of the PRC. The policy's commitment to national unity and integration over the maintenance of distinctiveness, realised through the vector of economic development, has the potential to realise changes of breathtaking scope and magnitude.

China's Tibet policy has evolved since the 1950s, but a national strategic dimension has remained at the core. In the TAR, implementation of the GWD is above all a political matter, imposed from the top down, designed for state interests. Ultimately China hopes to solve what it terms "the nationalities problem" in Tibet and the western regions through application of the GWD policy, "the necessary choice" for the situation $^{6}$. Tibet has been a final frontier for the Chinese nation-state, where local elements have contested Chinese political authority, as well as assimilation on other fronts, since the 1950's. Now China's leadership envisages a conclusive long-term strategy ${ }^{7}$, whereby the TAR and its population will finally be integrated seamlessly into the Chinese nation.

4 The potential local impact of the GWD is contested. On the Chinese government side is the official representation of the past, the current situation, and the future that should be constructed. On the other side is the unauthorised impression: the view on the ground for Tibetans of the past, the current situation and the expected future, a view kept largely private for fear of punishment. This paper will briefly consider perspectives from both sides of the contest, and suggest potential consequences of the new policy for Tibet's, and China's, future.

Historical perspective: contested identities

5 At the basis of the Sino-Tibetan contestation is the political status of Tibet in history. The intractable nature of this conflict shadows Chinese policy in the TAR and local reaction to it, no matter what the issue or the time frame. China's claim that Tibet is, and has long been, part of the Chinese motherland permeates official rhetoric and indeed virtually all Tibet-related unofficial publications in the PRC. In contrast to provincial units where political loyalties are not in doubt, official statements on GWD implementation in the TAR invariably refer to the historical dimension of Tibetan relations with China. By emphasising national security and stability as basic goals in GWD policy for Tibet, China acknowledges the fundamental issues at stake.

6 The CCP shares its ideological position on Tibet's inalienability from the Chinese nation-state with Chinese leaders since Republican times, when the Tibetan Government in Lhasa regarded Tibet as an independent polity. In 1950 the CCP enforced its view of Tibet's subordinate status with military invasion in the first instance, followed by dismantling of the existing political and social order and insertion of the same mechanisms for societal transformation being implemented in the rest of the PRC. Nominal autonomous status granted to Tibet did not, in practice, shield the region from all-encompassing re-ordering.

7 Today the state conceives its mission in implementing the GWD not just as historic, but as part of a historical process: the continuity of China's absorption [assimilation] of the western regions, and the restructuring of their demographic, cultural and economic characteristics: "Historically, large-scale western development is a major undertaking in China's development and will have a major impact on China's economic, political, and cultural life as well as a profound influence on ethnic relations of the western regions". 
Contemporary PRC historiography of the western regions generally supports the concept of the gradual evolution of these areas into integral components of the Chinese nation, a process whereby they become "Chinese" in a political and a cultural sense. The GWD now aims to strengthen the alignment of the Chinese nation-state on multiple levels, at times using such terms as "coagulability" and "centripetal" to describe the forces involved". These explanations justify the lack of need for special concessions within the GWD in areas like the TAR where history, culture, dominant ethnicity and China's designation as "autonomous" might logically suggest alternative policies. But as explained by a prominent Tibetan official, Ragdi, autonomy means "the fundamental political system by which our country resolves ethnic problems" (emphasis added) ${ }^{10}$, a formula highlighting an inherent GWD objective.

Tibetans who construe the past differently from the official line risk criminal prosecution, since any challenge to the unity of the motherland or the nationalities is unconstitutional and illegal. In responding to the GWD they see a fundamental conflict between the goal of strengthened integration and their own historical discourse, but their facility to express divergent views is vigorously repressed by the state's politicolegal apparatus.

Chinese leaders characterise the GWD as a national project expected to make its mark on history, and assert the historical and political legitimacy of their mission. Their awareness that Tibetan opposition exists and is an expected cause of friction has been built into the goals and methodology of the GWD project. The TAR 10th Five-Year Plan, for example, admits "the intensity and complexity of the struggle with separatism", calling it "a daunting challenge" which must be "tackled" the Anti-Separatism Struggle in Depth, Safeguarding Social and Political Stability"-is devoted to the matter. Whether Tibetans accept the Chinese historical discourse or not, the GWD aims to achieve a solution to the "nationalities problem" anyway. The development's invocation of state-endorsed history throws up an inescapable element of conflict at the local level in the TAR. The project addresses this in the strongest terms by integrating legal, political and socio-economic counteractions into its provisions.

Policy and political aims

11 In June 2001, the Party's top leadership convened the Fourth Forum on Work in Tibet, an occasionally-held event signifying the Party's intention to reinforce its policy concerning this distinctive component of PRC territory ${ }^{12}$. The Work Forum's significance lay less in the details of policy statements than in the context framing them: the primacy of national unity and development, the key role of the newlyadopted GWD policy in this goal, and the TAR's constituency within the GWD ${ }^{13}$.

Other policy conventions dovetailed with the Tibet Work Forum, consolidating both the TAR's position within national policy and the reach of Peking's plans into Tibetan affairs. Following the announcement of a new national development policy for the socalled "Western Region of China" in January 2000 and adoption of the Tenth Five-Year Plan in March 2001, the TAR's place in the new national strategy was laid out during 2001 in the TAR Government's Tenth Five-Year Plan (in early June), then the Fourth Forum on Work in Tibet (June 25th-27th), and finally during the celebrations in Lhasa for the 50th Anniversary of the Peaceful Liberation of Tibet in July ${ }^{14}$.

All official statements released from these events stress the TAR's integral importance in national strategy. Party General-Secretary Jiang Zemin declared at the Fourth Work 
Forum that development and long-term stability are the two major issues for work in Tibet, and that these in turn are "related to the strategic implementation of great western expansion, to national unity and social stability, to the unification and security of the motherland, and to our national image and international struggle... Safeguarding stability and development in Tibet as well as the unification and security of the motherland is an important political task of Tibet work" ${ }^{15}$. Such an openly political construct of the TAR's role in national security, through GWD formulation, distinguishes this region from those in the project ${ }^{16}$, both from the central government's viewpoint and in terms of local response. Yet the emphasis on the political dimension of development in Tibet is hardly a departure from preceding Party policy for the TAR: the Third Tibet Work Forum (July 1994) framed the Party-state role in equivalent terms: "The work in Tibet occupies a strategic position in the general task of the party and the state ... To accelerate Tibet's development is not only an economic issue of eliminating the gap between regional development but is also a political issue having an overall strategic interest" ${ }^{17}$. Under the GWD, policies and processes already in place for the TAR will be intensified rather than reconfigured.

In June 2000 Li Dezhu established the direct and unequivocal interdependence between carrying out the GWD as the correct means of developing the west, and protecting national unity as an essential element of succeeding with the project: "Only by carrying out the strategy of large-scale western development and accelerating development of ethnic regions will a solid foundation for strengthening national unity and protecting social stability be laid. Only by strengthening national unity and protecting social stability will a favourable social environment for carrying out the strategy of large-scale western development be created" ${ }^{18}$.

Hu Jintao contextualised this equation for the TAR a year later: "Tibet is in the southwestern frontier of the motherland, with a vast stretch of land and a most important strategic position. The development, stability and security of Tibet have a direct bearing on the fundamental interests of people of all ethnic groups in Tibet as well as ethnic solidarity, national unity and state security... Rapid economic development is the fundamental condition for realising the interests of all ethnic groups in Tibet and also the basic guarantee for greater ethnic unity and continued stability there" ${ }^{19}$.

For David Goodman, nation-building is an integral discourse of the project ${ }^{20}$. In Tibet, populated by a non-Han majority who have consistently shown themselves resistant to cultural and political integration with Chinese norms, the nation-building aspect underpins virtually all levels of GWD planning. Its colonialist traits, implicit in its developmental measures and the official rhetorical terminology of national unification, characterise centre-TAR interactions concerning implementation and goals of the GWD. Colonialist activities by China in areas of predominantly Tibetan settlement predate the PRC, let alone the GWD, but exploitative and demographic colonialism in Tibet does begin in the 1950s. The experienced realities of the relationship between the contemporary TAR area and China are not precisely paralleled by the imperial agenda of Qing times, which was essentially a politically expedient diplomatic arrangement, engineered to secure the then Tibetan polity as a buffer against Mongol, then AngloRussian threats to inner China. Now-and in a process intentionally accelerated under the GWD-China's agenda for the TAR involves multi-level integrationist, assimilationist and Hanificationist measures. The effects of similar strategies by the current and Republican Chinese states may be observed in Manchuria and Inner 
Mongolia, where deep demographic, economic and cultural transformations have taken place since approximately the turn of the twentieth century. The PRC's concept of "autonomy" does not clash with the aims of the process. Chinese official discourse privileges national unity over considerations of ethnic distinctiveness, and especially in current terms emphasises the historical inevitability of its various minzu evolving into the family of the Chinese motherland ${ }^{21}$.

For the TAR, the economic development component of the campaign, however seriously it will be promoted, has a strategic base: national stability through firmer integration of the TAR will enhance China's regional stability, which in turn will foster economic development and even foreign investment.

Cultural impact: demographics

The overwhelming majority ethnicity in the TAR is Tibetan, and that Tibetan ethnic culture contains significant features distinguishing it from that of the national Han majority. Assessments of Tibetan culture in reference to the GWD are presented as a couplet: recognition of difference, and the need for change. In an argument applied to the whole western region by Li Dezhu in 2000 and underscored for the TAR by Jiang Zemin at the 2001 Fourth Tibet Work Forum, culture will be made to fit the GWD framework of national security and economic development by means of the "new" socialist nationalities relations, which will promote social stability and national-and nationality-"coagulability"22. To achieve this, the Party leadership advocates a dual process of specifically-targeted, applied cultural policy measures and demographic changes resulting from overall policy. The most psychologically-charged dimension where the GWD may be expected to impact locally, therefore, is culture.

Since the arrival of the PLA in Lhasa in 1951, the Party has adopted a series of cultural polices, ranging from near-destruction to relative liberalism. Each aimed to transform Tibetan culture along Chinese state guidelines. Consistent with this trend, GWD policy asserts unequivocally that Tibetan culture must adapt to the new conditions and requirements of the GWD. Like former TAR leaders, the current provincial administration must take central directives as the basis for dealing with locallyrelevant cultural matters and engage in developmental objectives, including cultural ones $^{23}$. There is no question of the development paradigm adapting to local culture: Tibetan culture is a problem to be overcome, not a feature to be protected and nourished. Following high-level assertions of cultural impediments among the western regions' minority populations, it is often left to regional authorities to indict backward cultural characteristics standing in the way of successful realisation of the state's socioeconomic policy ${ }^{24}$. From Jiang Zemin's ideology of "socialist spiritual civilisation" 25 to explanations of Tibet's unsuitable ideological concepts from the TAR government chairman, Legqog ${ }^{26}$, cultural discourse for the TAR is moulded by the state's call for social stability, national unity and economic development.

Described as the sharing of cultures under the new socialist ethnic relations, cultural integration guarantees the spread of Chinese norms and values, which will assist GWD goals. Among other things the GWD project is about national minority populations becoming culturally more like the Han Chinese, attaining "culture with Chinese characteristics" 27 . Party policy leaves no doubt that cultural assimilation into the Chinese mainstream is a desirable outcome for Tibetans themselves.

21 Tibetans have lamented before that their cultural institutions, practices and values were under threat, but one pillar of the GWD heightens their concerns more than any 
other: the certainty of increased immigration from inner China. The anticipated population shift from east to west, poetically encapsulated as "the phenomenon of the peacock flying west" by Li Dezhu ${ }^{28}$, or more prosaically flagged as "encourag[ing] ... proper inter-regional population circulation" by the State Council ${ }^{29}$, is considered elemental to the success of the GWD ${ }^{30}$. In the TAR, with its historically homogeneous Tibetan population, substantial immigration will transform regional demographics.

Official statistics do not reflect the actual population in the region. The $6 \%$ of Han recorded by the 2000 census reflects only those Han whose legal place of permanent residence is registered as within the TAR. But local officials have admitted that Lhasa and Shigatse, the TAR's largest cities, have seasonal and undocumented Han populations of 100,000 and 50,000 respectively ${ }^{31}$, a number that approaches the officially recorded Han population for the entire $\mathrm{TAR}^{32}$. Even greater statistical anomalies exist: the total population of Bayi Township, for example, given as 16,000 in the mid-1990s $\mathrm{s}^{33}$, was reported in a government publication as 140,000 in $1997^{34}$, in an official county population of 26,000 .

Increased urbanisation is a key means by which the authorities plan to steer the economy in agricultural and pastoral areas towards marketisation and what is termed "socio-economic development" ${ }^{35}$. It is a goal for the country at large ${ }^{36}$, with urbanisation levels publicly projected at $50 \%$ by the year $2020^{37}$. By 2010 , the TAR anticipates urbanisation should rise to $20 \%^{38}$, an expectation facilitated by the provincial Five-Year Plan's proposal to create four major urban systems in the region. With the provincial capital Lhasa as the centre of an upgraded region-wide transportation, communications and energy network, the urban centres will provide "effective leadership" for their surrounding areas ${ }^{39}$. Given the overwhelmingly rural character of the TAR's Tibetans ${ }^{40}$, and the presence of sinicised towns already constructed throughout the region ${ }^{41}$, many Tibetans infer that this aspect of the GWD is intended to benefit migrants rather than the indigenous population. This frequently expressed opinion is supported by extensive development of new housing estates in Lhasa, Tsethang, Bayi and Shigatse, the TAR's largest towns, whose construction style reflects a Chinese architectural idiom, and whose occupants and construction workers so far are primarily Han Chinese. Events such as the First Lhasa-Sichuan Real Estate Expo held in Lhasa in September $2002^{42}$ corroborate the impression that developing the rental housing market, as advocated by the TAR 10th Five-Year Plan, has migrants from populous neighbouring provinces in its sights as investors and future residents. Urbanisation disturbs Tibetans not as a phenomenon as such, but because of the expected accompanying acceleration of population influx from interior China.

The level of in-migration implicit in GWD plans for the TAR represents a departure, at least in scale, from pre-reform Tibet policy. Many Tibetans educated within the Chinese system are aware that Chinese leaders including Mao and Deng saw Tibet as a potential destination for millions of Chinese settlers, but immigration did not begin on a large scale until 1992, when restrictions on private travel by PRC citizens were removed and economic migrants entered the region in unprecedented numbers ${ }^{43}$. The process has been escalating ever since, as recommended during the Third Tibet Work Forum, and is intended to intensify further under the GWD. While "immigration" is never explicitly mentioned in the TAR 10th Five-Year Plan, and while Tibetans are included among beneficiaries of economic progress, the model for constructing the future focuses on human resources that the TAR cannot provide. Economic migrants are not the experts 
encouraged to come to the TAR in official policy, but they do provide the main labour force for the GWD's market, construction, and resource extraction requirements, and are overwhelmingly Han Chinese. In official parlance, they comprise the "people of all nationalities" in Tibet, whose cultural concepts are not among those that stand in the way of market development like those of Tibetans ${ }^{44}$, and whose presence will contribute to "improving the quality of the population" ${ }^{45}$, assist economic acceleration, and guarantee a stable social order ${ }^{46}$. The ethnocentric discourse of economic development underpins the GWD's more practically applied measures.

Urbanisation and migration have been implemented successfully, from the state's point of view, in Inner Mongolia and Xinjiang, where a Han demographic now nearly dominates ${ }^{47}$. The unstated doctrine of great Han agriculturalism ${ }^{48}$, whose forces demographically and culturally transformed vast non-Han areas in the historical past and sometimes into the present, could be considered as morphing into great Han urbanisation under current policies. Han who have migrated, temporarily or permanently, to the TAR to date stay largely in urban environments which also, to date, duplicate the essentials of inner Chinese urban settlements, recent official endorsement for "stressing individual characteristics" in town construction notwithstanding ${ }^{49}$. But increased urbanisation plans for the TAR aim to accommodate not only Han migrants, even though these may well constitute the majority urban population in the future, as current trends suggest. Rural Tibetans are also expected to move to urban centres, according to state and provincial-level policy statements on projected socio-economic processes. Measures adopted to facilitate them such as reform of household registration ${ }^{50}$ and envisaged administrative changes whereby prefectures and counties will be "upgraded" to municipal status ${ }^{51}$ substantiate the impression that deep structural alterations to society are intended along lines familiar to the Han Chinese cultural landscape. Policy and ideational discourse link urbanisation with developing a modern, civilised society, whose features will then contribute to social stability, and its supposed attendant guarantee of national stability. For the Chinese state, migration and urbanisation mean creating an environment in unintegrated border regions like the TAR in which Chinese cultural characteristics will flourish, and in so doing propel the goals of the GWD. Studies elsewhere in China's national minority districts have shown that it is not Han Chinese migrants who find themselves under pressure to adapt to local culture and customs. As the social and political representatives of a dominant national majority, the expectation of past and present policies involving migration is that they will influence and change the society into which they move $^{52}$. The GWD's rhetoric offers the current form of political legitimisation for social change via demographic restructuring; the latest phase of China's civilising, integrating project in its non-Han areas.

Tibetans embrace the notion of economic development, but within a Tibetan milieu. The interlinkage between demographics, economics and politics is obvious to them. In the creeping sinicisation of the Tibetan autonomous prefectures of Qinghai, Sichuan, Gansu and Yunnan ${ }^{53}$, Tibetans in the TAR have ample evidence of the cultural dilution and marginalisation that occur under heavy Chinese immigration. Although the negative effects of immigration are denied by Party leaders ${ }^{54}$, Tibetans themselves dread the impact of large numbers of immigrants on their culture: privately they express this concern more than any other. While many embrace the principles of education and technical advance inherent in the notion of modernisation, they see the 
effects of GWD cultural policy not in policy terms as "civilising" 55 , but as a means by which Tibetan culture will be degraded and subsumed.

Religion

In June 2000, Li Dezhu identified the religious factor in self-identity and culture among the national minorities of the western regions as a prime obstacle to the smooth implementation of the GWD: "Historically, the western region was a sensitive region for ethnic relations. The negative impacts of some ethnic relations problems left over by history cannot be eliminated in the short term, but still require long-term effort. The religious influence of the western regions is far-reaching, and the complexity of managing ethnic relations has been increased by the intermingling of nationality and religious issues" 56 .

The nexus of religion, social culture and nationality issues addressed in policy statements and ideational expositions of the GWD recognises that precisely such problems are expected in the Tibetan environment, and they are frequently cited directly as "separatism". In the TAR, where Tibetans embrace Buddhism virtually universally, the state views the merging of separatism and religion as inimical to national unity and stability. Anti-separatist policies linking religion with threats to state security and development, built into the GWD to support the objectives of national unity and stability, are expanded to more specific measures within TAR policy. The Fourth Tibet Work Forum and the TAR 10th Five-Year Plan have adopted an assertive rather than reactive strategy in dealing with Tibetan separatism, described as moving from "basic security" to "long-term security" ${ }^{57}$. This progression entails strong anti-Dalai Lama rhetoric, continuation of existing "strike hard" and "patriotic education" campaigns, and more rigorous Party management of religious personnel, activities and institutions ${ }^{58}$.

Paradoxically, Tibetan culture and Chinese state ideology both link religion to national identity, the foundation on which their conflict rests. The state calls for religion and patriotism towards China to be intertwined, a condition that did not apply in premodern Tibet even when Qing emperors regarded Tibetan territory as an imperial protectorate. National party leaders from Jiang Zemin at the Fourth Tibet Work Forum to Li Dezhu in his strategic paper have directed that culture, inseparable from religion in Tibetan societies, must become supportive of Chinese ideological, political, and developmental objectives. Li Dezhu refers to development as a "cause", consistent with its political characterisation. TAR policy correspondingly construes the religious element in Tibetan culture in strategic terms, with a main battlefield, a target in the form of religious influence, and a goal of reducing the "negative effects of religion on the region's development and stability" ${ }^{59}$. It names the Dalai Lama as a malefactor, destructive not only to national unity but also to Tibetan Buddhism itself ${ }^{60}$, a portrayal deeply resented by Tibetans. Such official statements, which bind the goal of "building socialist spiritual civilisation" with the anti-separatist struggle and religion's negative influence, implicate religion and its management by the state in the wider goal of nation-building through social re-engineering, a process to be effected both from within religious circles and society at large ${ }^{61}$. As major provincial-level communiqués show, two years after adoption of the GWD the objective of controlling religious practice, institutions and personnel, including at the highest esoteric levels of religious leadership, remains a continuing priority ${ }^{62}$. The state's call for religion to serve state ideology and development plans strikes many Tibetans as inconsistent with their 
religious convictions, a conflict which they fear will hasten a future for their region which is decreasingly "Tibetan".

The economic future

The PRC's economic development agenda in the TAR builds on post-reform era factors implemented through successive Tibet Work Fora, namely increased demographic and economic links with inner China, local resource exploitation, and infrastructural construction. Within the provisions of the GWD, all are expanded and accelerated by "leap-style development" 63 . The theme of "speeding up" fits into the wider current discourse on style of development for national minority areas, in order to build equality with China's richer eastern provinces ${ }^{64}$. Zhu Rongji delivered the key statement at the Fourth Tibet Work Forum in 2001 on economic acceleration, identifying a "weak infrastructure" as the "main factor restricting economic progress in Tibet", and calling for construction projects in every key sector, improved exploitation of resources for industrial use, comprehensive readjustment of the agricultural and pastoral industries, heightened emphasis on tourism, and infusing the entire development process with improved science and technology ${ }^{65}$. By promising extensive preferential policies and generous state funding in all these areas, as well as for "political power at the grass-roots levels", Zhu left no doubt of the central government commitment to build the TAR's future within a primarily national framework.

31 Central funding and emphasis on infrastructural mechanisms to promote integration within the nation-state have characterised Tibet policy since the 1950s, and remain crucial to the form of the TAR's development. The level of state funding in the TAR under the 10th Five-Year Plan highlights state commitment, a situation not necessarily paralleled in other provinces subject to the GWD: the 37.9 billion yuan originally announced in August $2001^{66}$ was increased to 90 billion yuan in $2002^{67}$. To this may be added 26.2 billion yuan for construction of the Qinghai-Tibet Railway, an extraordinary engineering project decided, financed and executed by the state in pursuit of its national strategic interests ${ }^{68}$. Authorities expect its impact to be "far-reaching (...) in political, economic and military terms" ${ }^{69}$, a likelihood borne out by historical precedents of railway-building elsewhere such as the American West or Siberia. Integration of the TAR's economy into the national market is expected to transform the TAR from a marginal, backward economic position into a modern market-driven entity, in which the "people of all nationalities" contribute and share.

This reference to the TAR's multi-ethnic demographic (five times) is perhaps the most salient disclosure in the Plan's instructions on the future for the TAR, given the previous absence there of any significant numbers of any nationality other than Tibetan. Many provisions relating to economic development make sense only in the context of a significant influx of migrants: increased urbanisation, industrialisation, social security measures, trade along communications routes, expanded consumerism, resource exploitation, entrepreneurial links with interior provinces. The scale and nature of these goals could not readily be equated with either the size or the composition of the TAR's current population as it appears in the official portrayal: 2.62 million people in a 1.2 million square-kilometre area (population density 2.2 ), $80 \%$ rural (85\% for ethnic Tibetans) $)^{70}$, a $32.5 \%$ illiteracy rate $^{71}$, and actual purchasing power of rural incomes lower than for the early $1990 \mathrm{~s}^{72}$. 

engaged in the TAR's economic development suggests a future in which Tibetans do not play a significant role on their own terms. The TAR 10th Five-Year Plan describes the goals and methods of development to be implemented in the TAR within the framework of the national GWD project, but these are not tailored to local culture. Nor are mandates negotiable: potential alternative development models are not acknowledged $^{73}$. The state-subsidised exploitation of Tibetan resources to meet domestic demand is aimed primarily at supporting Chinese industry, not Tibetan sustainable development, a situation recognised as a problem even by Hu Angang, one of the chief intellectual advocates of the $\mathrm{GWD}^{74}$. Though increasingly opened up to private investors, resource extraction is still governed by the constitutional appropriation of all natural resources by the state ${ }^{75}$, and removes valuable regional assets to the greater benefit of the interior than the region itself. Tibetans may covertly complain of this process but it is generally too sensitive a subject for public airing, open to interpretation as a colonial dynamic and ultimately an issue of nationalism ${ }^{76}$.

Given the divergent assessments of many local Tibetans and official discourse on the likely impact of the GWD project, what evidence emerges so far to support either view? The TAR Government Work Report for its last five years in office, delivered in January 2003, recognised limitations, thus far, of moving towards most of the project's goals, by admitting briefly but frankly: "Economic restructuring proceeds slowly, and the advantages of the industries with their own characteristics have yet to be fully developed; development of the industrialised operation of agriculture and animal husbandry remains slow, and the channels for peasants and herdsmen to increase income are not wide enough, early preparations for projects lag behind, and the experience in the construction and management of major projects is lacking; the social security system is still imperfect, and the employment situation is not optimistic; there is still a gap in the implementation of various preferential policies, and the investment climate needs to be further improved; the number of trained personnel is not enough, and their structure irrational; some departments and localities lack creativity in doing work, and the work style of the contingents of cadres still needs to be strengthened; and the tasks to oppose separatism and safeguard social stability remain very difficult".

Simultaneous with this picture, reported statistics show a $10.9 \%$ growth rate for 1998-2002 $2^{77}$, a speed attributed by a senior TAR Government leader to construction of key projects with investment from the central government ${ }^{78}$. But urban incomes $(7,119$ yuan) are five times higher than rural (1,404 yuan), which are the lowest in the PRC and apply to $85 \%$ of the TAR's population. Although provincial leaders express awareness of the troubling urban-rural divide and the marginalisation from socio-economic benefits this implies for the majority of the Tibetan population, signs do not exist as yet that the state will not privilege its own priorities over such local concerns.

Not only do local preferences or expectations have no inherent status against the state's developmental determinations as expressed in policy and its supporting laws ${ }^{79}$, but the particularities of economic development under the GWD carry implicit Chinese cultural norms which may undermine Tibetan practices in fundamental ways. Tibetan culture, especially through the tourist industry ${ }^{80}$, should become an industrialised commodity adapted to the needs of the socialist market economy. Agriculture and pastoralism, the economic mainstays for the majority of Tibetans in the past and present, will face reconfiguration and recontextualisation by changes in regional 
market dynamics over which farmers and herders themselves will have virtually no control. The settlement of nomadic pastoralists ${ }^{81}$, sometimes compulsory and sometimes unavoidable, implemented in varying degrees in the TAR since before the Great Leap Forward ${ }^{82}$ and currently promoted under the provincial Plan ${ }^{83}$, particularly concerns Tibetans, for whom this way of life has embodied cherished cultural and ecological values ${ }^{84}$. Precedents for sweeping alteration of pastoral production and culture already exist elsewhere in the PRC, notably the Inner Mongolia Autonomous Region, where pastoralism now symbolises a romanticised embodiment of Mongol identity, but is engaged in by relatively few Mongols ${ }^{85}$.

Law

The PRC's development plans for the TAR rest on constitutional provisions and an emerging grid of laws that will ensure a top-down implementation of the GWD and ensure the process will not be disrupted by grass-roots complaints. The main determinants of the legal environment in which the GWD will be implemented in the TAR are:

- (a) a Law on Regional National Autonomy that requires governments of nominally autonomous areas to follow instructions from higher levels of government and hasten to fulfil policy directives (Article 7)

- (b) local legal reforms that will be carried out so the state has the unimpeded right to carry out its policies, but without provision for citizens to object;

- (c) the national Constitution, which forbids any act the state deems not to be in its "interests" (Article 54).

Perhaps ironically, government assertions that legal mechanisms and safeguards will be developed in tandem with the GWD are not intended to protect citizens, nor to ensure the individual's right to seek judicial review of policy or implementation, but to guarantee the state's right to exert its prerogative to transfigure national minorities and their homelands. Some PRC legal scholars critiqued the revised Law on Regional National Autonomy, adopted in February 2001, as insufficiently attentive to the legal relationship between organs of higher authority and those in the autonomous units ${ }^{87}$. But by codifying the plan in a legalistic framework, the PRC can claim that the GWD is being implemented under "rule of law": "At the same time, we must actively provide assistance to all levels of judicial departments for the prompt introduction of rules and regulations and promulgation of superior policies for the minority nationalities and ethnic regions during large-scale western development. They must use legal methods to provide legal guarantees for the implementation of these policies and safeguard implementation of the strategy of large-scale western development with laws and regulations" $"$.

The position is echoed at provincial level in the TAR 10th Five-Year Year Plan: "Local law-making must be expanded, with emphasis on formulating a body of local laws and regulations compatible with the socialist market economy"... "We must intensify law enforcement and raise the standard of law enforcement in order to create a sound legal environment for our region's participation in the development of the western region and for preserving social stability" ${ }^{\prime 9}$.

The February 2001 revisions to the 1984 Law on Regional National Autonomy were passed by the NPC just one year after the announcement of the GWD project. This was hardly a coincidence: according to a vice-director of the Standing Committee of the NPC, the revisions were intended to facilitate implementation of the project's 
requirements in national minority regions ${ }^{90}$. Revisions to the Law show a discernible shift of emphasis from protection of local socio-cultural and economic interests to a goal of "solving problems" with respect to nationality solidarity ${ }^{91}$. While many clauses in the revised Law give organs of self-government the right-indeed the responsibility -to organise and develop various types of social, cultural and economic undertakings, the framework in which these are enacted is set by the state. Language in the revised Law echoes the essential policy formulations of the GWD: integration and socialist modernisation, resolving the ethnic issue, developing the socialist market economy, safeguarding the national unity, and so $\mathrm{on}^{92}$, describing more what is required of TAR officials and ordinary citizens than what they may aim for themselves. Even as stated formulations of policy and law are designated as "autonomy", actual practice takes the TAR towards integration.

41 Local culture, politicised in national minority regions as backward, potentially dangerous and obstructive to most of the state's aims in GWD as already discussed, carries especial difficulties in the TAR because of its religious component, and that component's association with a non-Chinese national identity. Nationwide legal restrictions on religious practice are enforced there with greater frequency and sometimes ferocity than is generally the case in the Chinese demographic heartland, and policy statements issued in relation to the GWD make clear the continuing commitment to pervasive legal controls. Renewed political dissent that has erupted in the TAR since the late 1980s, characterised in terms of Tibetan nationalism by both sides, has incurred severe legal penalties under State Security and PRC Criminal Law, as well as political campaigns targeting aspects of religious practice and expression as subversive to national security. Many sections in current state and provincial policy, inclusive of the GWD, emphasise official intolerance of religious culture which falls outside Party-established norms ${ }^{93}$.

42 The PRC government believes that through the GWD it will ensure stability and prosperity in the western regions. Through the Constitution and the politico-legal apparatus they exercise a statutory right to rule Tibetans as citizens of the Chinese motherland. Laws have been created specifically to facilitate and validate central control. An expectation of ethnic conflicts and separatist sentiments, sometimes coded in terms such as "contradictions among the people in the new period"94 or overtly signified in measures for increased security forces in the border areas, informs the legal support system for implementing the GWD, as language in policy and law guides the national minority areas alike along a state-directed path of socialist modernisation and national integration.

Solving the nationalities' problem

In framing the future of the TAR-a nominally autonomous region with a history of separate self-identity-within a context of national security and stability, the GWD acknowledges the underlying political contestation between the state and many Tibetans. This political element, underpinned by the TAR's original demographic homogeneity and isolation from any centres of Chinese population and culture, makes implementation of the project there locally significant less in economic than in cultural terms. The GWD, in its cultural policy, appears to be pursuing parallel agendasintegration and rhetorical adherence to cultural diversity-which nevertheless stream towards the ultimate goal of national unity. Though both are claimed to be integral to the GWD, in some regions-certainly the TAR-an innate conflict exists in promoting 
these stated aims. While recognising the multi-ethnic nature of the Chinese state, the state authorities intend to manage multiculturalism in ways that will, they hope, ensure it does not hinder wider developmental and strategic objectives.

Preferred methodology for meeting goals, and the preferential term for these, is "development", for which an all-encompassing power is identified. "Development is the last word" in facilitating the GWD"95, "the foundation for settling all the issues of Tibet" ${ }^{96}$, and ideationally the "infallible truth" for creating "stability in the new era" ${ }^{97}$. Yet "development" both serves and defines an over-arching state-building, assimilationist project; a project with colonialist processes. Amidst the developmental paradigm, the question of safeguarding autonomy in regions thus designated does not arise. The Centre can develop the TAR regardless of its nominal autonomy, since this status grants the right to participate in national projects of development and unification, not the right of abstinence. Implications in some provincial-level releases that local needs are not being met suggest that the national GWD project, like state policy affecting the TAR in the past, seems prepared principally to address its own mandates there.

Solving the nationalities problem, as one of them, cannot but have essentialist cultural overtones in a region whose indigenous culture exhibits persistent tendencies towards non-integration. The state anticipates that its project will likely provoke deep objections in the TAR, and requires that opposition be "handled properly and promptly" before it can "affect national unity and social stability" 98 . At state and provincial levels, authorities are suggesting that Tibetan opposition would not be rooted in grass-roots rejection of Chinese developmental models, but in the inherent weakness of Tibetan culture, as well as outside interference. Whatever its source, there will be no hesitation in using powerful means to counter dissent or resistance. Policy and law supportively ensure the "smooth implementation of the strategy of large-scale western development" ${ }^{\prime 99}$. In its reliance on increased immigration from interior China, economic development accelerated by state-mandated policies and investment, the merging of TAR markets into the national mainstream, and open calls for cultural assimilation, the GWD's implementation will rely on measures introduced to Tibetans during earlier chapters of policy for their region. The project's terms provide merely the latest reference point for carrying these measures out, while high levels of funding underscore the state's determination to realise current policy proposals for the TAR. Among these, an altered demographic base and stronger political integration into the Chinese state seem likely to be deliverable. Future assessments of the PRC's success in "solving the nationalities' problem" in Tibet will call for an examination of the applicability of the term "Tibetan" to the prevailing culture of the region's inhabitants.

\section{NOTES}

1. This paper has been presented at the international conference "Opening Up the West: China's Regional Development Policy", organised in Hamburg May 8th-10th 2003, by The China Quarterly (London); the Institute of Asian Affairs of Hamburg (Germany) 
and the Institute for International Affairs, University of Technology of Sydney (Australia).

2. The PRC uses "Tibet" to refer only to the Tibet Autonomous Region (TAR), a provincial-level unit of administration set up in 1965, inclusive of the area of Tibet west of the Yangtze River previously under the jurisdiction of the Tibetan government in Lhasa. Other predominantly ethnic Tibetan areas were incorporated into four Chinese provinces (Yunnan, Sichuan, Gansu and Qinghai), and usually designated Tibetan Autonomous Prefectures. For convenience this paper will adhere to PRC usage.

3. Li Dezhu, Minister of State Ethnic Affairs Commission: "Large-Scale Development of Western China and China's Nationality Problem" (Xibu da kaifa yu woguo minzu wenti), Qiushi, June 1st 2000, No. 11, pp. 22-25 [FBIS trans].

4. Li Dezhu, op. cit., Section 3.

5. This paper is based on informal interactions with a wide spectrum of informants, including officials, professionals, religious personnel, security personnel, entrepreneurs, teachers, students, and rural and urban dwellers, carried out in a highly sensitive environment. Protection of informants' identities has therefore been considered requisite in all cases. Views expressed as "Tibetan" or "local" represent encapsulations of such opinions evidenced over a long period of observation by the author in the TAR and other Tibetan areas of the PRC, from 1980 through 2002.

6. Li Dezhu, Li Dezhu, op. cit., Section 1.

7. Hu Angang suggests a 50-year span to achieve GWD goals (Zhang Yangxin and Feng Qijian, "PRC Economist Hu Angang Stresses Need to Help Poor in Developing Western Region", Peking, Xinhua, HK Service, October 20th 2000). Li Dezhu also envisages GWD as a work of "several generations".

8. Li Dezhu, op. cit., Section 2. See also "State Council Notice on Implementing Policies and Measures to Develop West China", Peking, Xinhua, December 27th 2000:

"Developing the west is a magnificent piece of systems engineering and a daunting historic mission". [FBIS trans], and Jiang Zemin on developing the West as an unprecedentedly difficult historic responsibility, in Renmin ribao, June 19th 1999, cited in Gao Zhao Ping et al (eds.), Zhongguo xibu da kaifa zhanlüe yanjiu (Studies on Great Western Development Strategy), Xining, Qinghai renmin chubanshe, 2000, p.18.

9. Li Dezhu, op. cit., Section 2. The term translated by FBIS as "coagulability"-ningjuliappears twice in Li Dezhu's original Chinese text in Qiushi. Jiang Zemin was already using the term ningjuli in 1999 in the context of Central-Western regional development; specifically the necessity of developing the PRC's national minority regions in order to promote nationality equality, prosperity and economic development. These in turn would strengthen coagulability among China's nationalities, thereby maintaining stability and consolidating the motherland's border defences (Renmin ribao June 19th 1999, cited in ZhongguoXibu da kaifa zhanlue yanjiu, p. 17).

10. Lhasa, Xizang ribao, August 7th 2001. Ragdi's posts in 2001 included TAR Party Committee Standing Committee Deputy Secretary and TAR People's Congress Standing Committee Vice-Chairman.

11. Lhasa, Xizang ribao, June 9th 2001: "Outline of 10th Tibet Five-Year Plan of Economic and Social Development".

12. Earlier Tibet Work Fora were held in 1980, 1984 and 1994.

13. "Jiang Zemin, Zhu Rongji Address CPC, State Council Tibet Work Meeting in Beijing”, Peking, Xinhua, June 29th 2001. 
14. The signing of the 17-Point Agreement between the Tibetan and Chinese governments, which for China marks the Peaceful Liberation, took place on May 23rd 1951, but Peking VIPs, including Hu Jintao, went to Lhasa for official celebrations in July.

15. Xinhua June 29th 2001.

16. With the exception of Xinjiang, where ethnic and cross-border tensions currently pose greater concerns for the Chinese Government than in the TAR.

17. Lhasa, Xizang ribao, August 6th 1994.

18. Li Dezhu, op. cit.

19. Xinhua, July 19th 2001.

20. David S.G.Goodman, "The Politics of the West: Equality, Nation-Building and Colonisation", in François Godement (ed.), La Chine et son Occident (China and its Western Frontier), Paris, Centre Asie IFRI, 2002.

21. See for example introduction to Zangzu jianshi (A Brief History of the Tibetan Nationality), Xizang renmin chubanshe, 2000 (original edition 1985), or Hu Jintao's speech at the 50th Anniversary of the Peaceful Liberation of Tibet, Beijing, Xinhua July 19th 2001.

22. Li Dezhu, op. cit., Sections 2 and 4.

23. See for example TAR Government Work Report delivered January 2003: "The 16th Party Congress held in November last year (...) mapped out plans for all the work of developing socialist economy, politics, and culture with Chinese characteristics".

24. Interview with Legqog, Chairman of TAR People's Government, in Qiushi, September 16 th 2000.

25. Jiang Zemin at Fourth Tibet Work Forum, Xinhua June 29th 2001.

26. Qiushi, September 16th 2000.

27. See note 25 above.

28. Li Dezhu, op. cit.

29. State Council Notice on Implementing Policies and Measures to Develop West China, policy point 5 (1).

30. Some Chinese research articles position migration under GWD within the historic population movement westwards from the Chinese heartland during imperial "opening up" campaigns, but adding the sanctioning dimension of the GWD's modernisation goals (see essays in Mao Gongning and Wang Tiezhi (eds.), Minzu quyu zizhi xinlun [New Discussions on Nationality Regional Autonomy], Peking, Minzu chubanshe, 2002).

31. washingtonpost.com, World in Brief, August 8th 2002 (Reuters), "Chinese to Outnumber Tibetans in Lhasa", quoting Jin Shixun, deputy director general of Tibet's Development and Planning Commission: "At the moment the population here in Lhasa stands at around 200,000. About half of them are the migrant population... there will certainly be a large increase in these numbers". Shigatse reference: Damien McElroy, "Tibetans yearn for Dalai Lama", London, Daily Telegraph, September 16th 2002.

32. 160,000 by the 2000 Census.

33. Xizang zizhiqu dituce [Atlas of the TAR], Peking, China Cartographic Publishers, 1996, p. 154.

34. China's Tibet, Vol. 8, No. 6 (1997), various reports on Linzhi (Tib.: Nyingtri) County. 35. TAR 10th Five-Year Plan, Chapter 7 "Intensifying Urbanisation and Raising the Level of Urbanisation", in Xizang Ribao, June 9th 2001.

36. See PRC $10^{\text {th }}$ Five-Year Plan, Chapter 9. 
37. Zeng Peiyan, Minister of the State Development Planning Commission, and Zeng Xinli, deputy director of the Policy Research Office of the CCP Central Committee, cited in peoplesdaily.com Dec 6th 2002.

38. Xibu da kaifa zhinan: tongji xinxi zhuanji (Guide to Great Western Development: statistics and information special edition), NPC Development Research Centre, China Business Appraisal Association, National Statistical Bureau Comprehensive Office (comp.), Peking, Zhongguo shehui chubanshe, June 2000, p. 374. In 2000 the urban population of the TAR was already officially recorded as $19 \%$, but the $20 \%$ referred to in this context suggests increased urbanisation for farmers and herders, who are mostly Tibetan, from $15 \%$.

39. TAR 10th Five-Year Plan, Chapter 7.

40. $85 \%$ according to the 2000 Census. The total rural proportion for the TAR is $81 \%$, the highest provincial-level rural percentage in the PRC and the only province exceeding 80\%: closest are Guizhou, Yunnan and Henan at 76\% (China Population Statistics Yearbook 2001, Peking, China Statistics Press, 2001, p. 51).

41. Such as Bayi (Linzhi) mentioned above, described in China's Tibet, Vol. 8, No. 6, 1997: "With aid from Guangdong and Fujian provinces, the new town has arisen from almost nothing ... Before the town had become what it is today, Bayi was reminiscent of the few tattered villages lining the Nyang River in centuries past. The local residents lived on subsistence farming and animal husbandry. When life was almost meaningless, this part of the world was deadly quiet. But this existence has become history. This area is now a modern town with a population of 140,000. It has been just one year since Bayi began to don this new outlook. Its pebbled paths have made way for concrete streets. Its tattered huts have become modern apartments and commercial buildings.

Guangdong Road, Fujian Road, Zhuhai Road, Hong Kong Street and three others, as well as Xiamen Square and Zhujiang Market, were built in 1996 .... Some 110,000 $\mathrm{m}^{2}$ of residential areas have been interspersed with beautiful gardens. These projects have involved a total outlay of some 120 million yuan". This report gives an indication of the speed with which such urban construction is possible, as well as some Chinese ethnocentric cultural judgements.

42. Ben Dolven, “Tibet: Hope Springs Eternal”, in Far Eastern Economic Review, September 26th 2002.

43. As reported in Zhongguo Xinwen She, July 3rd 1993. See John Kransky, "Central Lhasa and migration: economic development and social consequences", Provincial China, No. 2, October 1996, pp. 16-44. Between the Fourth (1990) and Fifth (2000) Population Census of the PRC, the Han Chinese population in the TAR increased $92 \%$, from 80,837 to 155,300 . These figures of course represent the official residents, not the thousands of unregistered economic migrants whose presence, temporary or ultimately permanent, critically affects the socio-economic life of the region.

44. Interview with Legqog in Qiushi, September 16th 2000.

45. "Low" population quality in the western regions, although equated openly with low education levels, is also readily aligned with arguments referring to the developmental need for "talented personnel" from the east. See, for example, Liu Jiaqing, "Analysis of Demographic Environment in the Context of Development in Western China", Renkou Yanjiu (Population Research), July 1st 2001, pp. 46-50; and Ga Baoying, "Some Factors Restricting the Development of Ethnic Areas in the Exploitation of West China", Qinghai Minzu Yanjiu (Qinghai Nationalities Research), Vol. 13, No. 2, July 2002. 
46. TAR Government Work Report, "Suggestions on the work of the next five years", section 2 (F): "It is necessary to (...) bring in urgently needed personnel from outside the region in order to provide a personnel guarantee for achieving development by leaps and bounds and long-lasting order and stability". (Lhasa Xizang ribao, January 29th 2003).

47. Rapid Han Chinese migration to Inner Mongolia had begun at the end of the Qing Dynasty, especially after 1902: in 2000 Han Chinese constituted $79.2 \%$ of the population. In Xinjiang the Han Chinese population rose from $6.7 \%$ in 1949 to $40.61 \%$ in 2000.

48. Almaz Khan, "Who are the Mongols? State, Ethnicity, and the Politics of Representation in the PRC", in Melissa J. Brown (ed.), Negotiating Ethnicities in China and Taiwan, Berkeley, University of California Press, 2001, p.128, n.7: the author uses the term "great Han agriculturalism" to refer to the agricultural ideology of the Chinese both historically and in its modern context in state politico-economic policies.

49. TAR 10th Five-Year Plan, Chapter 7.

50. PRC 10th Five-Year Plan, Chapter 9; TAR 10th Five-Year Plan, Chapter 7.

51. TAR 10th Five-Year Plan, Chapter 7; TAR Government Work Report, section 2 (E).

52. Mette Halskov Hansen, “The Call of Mao or Money? Han Chinese Settlers on China's South-western Borders", The China Quarterly, No. 158, June 1999, pp. 394-413.

53. For a report on developmental effects in these areas during the mid-1990s, see Steven D. Marshall and Susette Ternent Cooke, Tibet Outside the TAR, Washington, Alliance for Research in Tibet (ART), 1997, CD-ROM.

54. TAR Executive Deputy Party Secretary in Xizang ribao, August 7th 2001.

55. Li Dezhu, op. cit;; TAR 10th Five-Year Plan, Chapter 17, and implication by many other leaders. For example see Jiang Zemin on the importance of carrying out the Party's nationality and religious work as part of successfully implementing the GWD (Jingji cankao bao [Economic Reference News], June 22nd 2000, cited in Zhongguo Xibu da kaifa zhanlue yanjiu, pp. 23-26).

56. Li Dezhu, op. cit., Section 2.

57. Jiang Zemin at Fourth Tibet Work Forum (Xinhua, June 29th 2001).

58. See Jiang Zemin's speech at Fourth Tibet Work Forum (Xinhua, June 29th 2001); TAR 10th Five-Year Plan, Chapters 17, 18, 19; and TAR Government Work Report, section 2 (4). "Earnestly do a good job in nationalities and religious work".

59. The TAR 10th Five-Year Plan deals with the issue in Part 7, Spiritual Civilization, Democracy, and Legal System: Chapter 17 Accelerating the Construction of a Socialist Spiritual Civilisation, Chapter 18 Doing a Good Job in Nationality, United Front, and Religious Work and Further Solidifying National Unity, and Chapter 19 Conducting the Anti-Separatism Struggle in Depth, Safeguarding Social and Political Stability.

60. "We must expose his political reactionary character and religious hypocrisy. We must clearly recognise the Dalai for what he is, the chieftain of a group of political separatists plotting to achieve Tibetan independence, the faithful tool of anti-Chinese forces in the world, the ultimate source of social unrest in Tibet, and the biggest roadblock to the creation of normal order in traditional Tibetan Buddhism". (TAR 10th Five-Year Plan, Chapter 19).

61. Through patriotic education campaigns in lay and religious communities, adapting religion to suit socialism, and spreading the principles of socialist spiritual civilisation. Party members are still prohibited from having religious belief, a directive which presents difficulties for many Tibetan cadres. 
62. That is to say, management of potential religious leaders: "It is necessary to strengthen leadership over the work concerning reincarnation of Living Buddhas and attach great importance to the training and education of Living Buddhas" (TAR Government Work Report).

63. Jiang Zemin at the Fourth Tibet Work Forum; TAR 10th Five-Year Plan.

64. See, for example, Chen Kuei (Chinese Academy of Social Sciences, Western Development Research Centre), Xibu kaifa da zhanlue yu xin silu (Western Development's Great Strategy and New Thinking), Peking, Central Party School, 2000, Chapter 3.

65. Fourth Tibet Work Forum (Xinhua June 29th 2001).

66. Assistance and subsidies during the 10th Five-Year Plan (Interview with Legqog in Hong Kong Ta Kung Pao, August 9th 2001). Later elaborated by Legqog as 31.2 billion yuan for key infrastructure projects, and 36.9 billion yuan in fiscal subsidies (Xinhuanet, September 16th 2002).

67. Xinhuanet, September 16th 2002. 90 billion yuan is significant in comparison to the 20 billion yuan given as total central investment in the TAR in the 40 years before 1994 (Zhongguo xinwenshe, Peking, June 28th 1994).

68. The idea of a railway from inner China into Tibet was first mooted by Sun Yatsen, and later revived by the CCP in the 1950s. The Xining-Golmud section was started in 1958 , re-started in 1979, and opened to traffic in 1984. Technical obstacles to construction on the Golmud-Lhasa section have now reportedly been overcome, and work began on the line in June 2001.

69. Vice-Minister of Railways, Sun Yongfu, in Xinhua, March 7th 2001.

70. Zhongguo renkou tongji nianjian 2001 (China Population Statistics Yearbook 2001), Peking, China Statistics Press.

71. Zhongguo renkou tongji nianjian 2001, p.50.

72. See TIN News Update, February 6th 2003, "Rural standards of living in the TAR still below 1992 levels".

73. Some PRC economists are growing concerned about the suitability of the macromodel of development for Tibet, but space limits discussion of their arguments in this paper.

74. Hu Angang, "The Problem of Selecting the Correct Path for Tibetan Modernisation", China Tibetology, No. 1 (January 2001), pp. 3-26 [trans. Tibet Information Network]. 75. PRC Constitution, 1982, Section 1, Article 9: "Mineral resources, waters, forests, mountains, grassland, unreclaimed land, beaches and other natural resources are owned by the state"; a clause raising sensitive political issues for Tibetans who contest the PRC's sovereignty in Tibet. The PRC Constitution (Article 118) and the Mineral Resources Law (1986, amended 1996) provide only that the state shall give "due consideration" to the interests of nationality autonomous areas when exploiting natural resources there. The revised Regional Nationality Autonomy Law (2001), while advocating "a certain level of compensation" to such areas for the extraction of their natural resources, also declares that resource exploitation in these areas will be governed by central policy ("unified plans") and market demand, supported by fiscal subsidies from the state (Wang Chi and Shen Lutao: "Important Amendments Are Made to the Law of Regional National Autonomy", Xinhua, Peking, February 28th 2001). 76. Legal punishment can arise from expressing such views. For example, in 1996 in Seda (Tib.: Serthar) County, in the Ganzi (Kardze) Tibetan Autonomous Prefecture in Sichuan, a Tibetan lama received a six-year sentence for alleged pro-independence activities. He denied that charge, though he had written letters to local authorities 
critical of gold mining near his monastery, complaining that the mining caused environmental damage, and that local Tibetans were not sharing in ensuing economic benefits. See Mining Tibet: Mineral Exploitation in Tibetan Areas of the PRC, Tibet Information Network, London 2002, pp. 103-104.

77. "Tibet reports double-digit growth", Xinhua, January 13th 2003.

78. "Tibet leads western China in economic growth", Xinhua, December 10th 2002.

79. The exercise of regional autonomy receives minimal attention in the revised Regional Nationality Autonomy Law, focusing on "solving problems" in regional social and economic development and thereby "promoting nationality solidarity". (Xinhua, February 28th 2001).

80. TAR 10th Five-Year Plan, Chapter 4. Tourism was made a pillar industry for the TAR in 1996, so the GWD's invocation of its economic potential through harnessing and adapting local non-Han culture is not an innovation but an intensification and acceleration of an existing approach here and in other national minority areas: Guizhou's experience of ethnic tourism is discussed in Tim Oakes, "Selling Guizhou: cultural development in an era of marketisation", Hans Hendrischkie and Feng Chongyi (ed), The Political Economy of China's Provinces: comparative and competitive advantage, London, Routledge, 1999, pp. 31-72. Current indications of the TAR's tourist market point overwhelmingly to the domestic tourist pool: over half a million domestic tourists-more than four times the number of foreign tourists-visited the TAR in 2001 (TAR Government Work Report for 2002), and over six times as many in 2002 (various Xinhua reports). 1.16 million domestic and 240,000 foreign tourists are expected in 2005. Under these circumstances, adaptation of the tourist industry to market taste seems likely: proliferation of hotels in Lhasa, built and used by personnel from inner China, and the fact that more tourist enterprises in the TAR are run by Chinese than Tibetans, bear out such a trend at present.

81. TAR 10th Five-Year Plan, Part 2, Chapter 2.

82. George Ginsburgs and Michael Mathos, Communist China and Tibet: The First Dozen Years, The Hague, Martinus Nijhoff, 1964, pp. 153-154.

83. TAR 10th Five-Year Plan, Part 2, Section 2.

84. See Robert B. Ekvall, Fields on the Hoof: Nexus of Tibetan Nomadic Pastoralism, New York, Holt, Rinehart \& Winston, 1968; also Geoffrey Samuel, Civilised Shamans: Buddhism in Tibetan Societies, Washington and London, Smithsonian Institution Press, 1993.

85. In the 1980 s only $18 \%$ of Mongols were classified as pastoralist $(448,020)$, or $2.3 \%$ of the total Inner Mongolian population, which is currently 79\% Han Chinese. For a penetrating analysis of Mongol identity in the IMAR, see Almaz Khan, "Who Are the Mongols? State, Ethnicity and the Politics of Representation in the PRC".

86. Article 7: "The organs of self-government of national autonomous areas shall place the interests of the state as a whole above everything else and make positive efforts to fulfil the tasks assigned by state organs at higher levels". (Law of the PRC on Regional National Autonomy 1984).

87. See, for one example, Wei Yiming, "Defects of the Amendments of the Law of Autonomy of the Minority Regions", Shanghai Faxue (Shanghai Legal Studies, journal of the East China Institute of Political Science and Law), August 10th 2001, pp. 20-23 (FBIS trans September 13th 2001).

88. Li Dezhu, op. cit., Section 5.

89. TAR 10th Five-Year Plan, Part 7, Chapter 17. 
90. Tomur Dawamat, “Jiejue Zhongguo minzu wentide chenggong zhi lu” (The road to successful solution of China's nationality problem), Minzu quyu zizhi xinlun, p.15.

91. Wang Chi and Shen Lutao, "Important Amendments are Made to the Law of Regional National Autonomy”, Xinhua February 28th 2001 (FBIS).

92. See Preface, revised Law on Autonomy of Minority Nationality Regions, 2001.

93. Religious policy, and its enforcement through administrative regulation and law, are both ultimately determined and managed through the CCP at state level, involving primarily the Religious Affairs Bureau, the United Front Work Department, and the Public Security Bureau.

94. TAR Government Work Report, section 2 (3), “Turn the basically stable social situation into one featuring long-lasting order and stability".

95. Li Zibin, "Blaze a new road of faster development", in Qiushi, February 16th 2003

(FBIS trans). The author is vice-minister in charge of the State Development Planning Commission and deputy director of the State Council Office for Western Development.

96. TAR Government Work Report, "Suggestions on the work of the next five years".

97. TAR 10th Five-Year Plan, Section 1, "Guiding thoughts and principles".

98. Li Dezhu, op. cit.

99. Li Dezhu, op. cit.

INDEX

Thèmes : politique 